http://doi.org/10.35784/iapgos.911

\title{
METHOD FOR ASSESSING THE STRUCTURAL RELIABILITY OF NETWORKS WITH UNDETERMINED TOPOLOGY
}

\author{
Nina Kniazieva, Alexey Nenov, Irina Kolumba \\ Odessa National Academy of Food Technologies, Faculty of Computer Engineering, Programming and Cyber Security, Odessa, Ukraine \\ Abstract. This paper shows the relevance of the task of assessing the structural reliability of networks with undetermined topology. Proposed is a method \\ for assessing the structural reliability of networks of undetermined topology based on taking into account the basic structural characteristics of the \\ network (the number of nodes and branches, the degree of network connectivity, the maximum allowable rank of paths, and others). To obtain an estimate \\ of the structural reliability for a network of any dimension and any topology, expressions are proposed in the scientific research to determine the number \\ of paths of various ranks, which must be taken into account when calculating the structural reliability index by the upper and lower bounds method.
}

Keywords: network of undetermined topology, structural reliability, route rank, number of routes of a certain rank, upper and lower bounds

\section{METODA OCENY STRUKTURALNEJ NIEZAWODNOŚCI SIECI O NIEOKREŚLONEJ TOPOLOGII}

Streszczenie. Ten artykut pokazuje znaczenie zadania polegającego na ocenie niezawodności strukturalnej sieci o nieokreślonej topologii. Proponowana jest metoda oceny niezawodności strukturalnej sieci o nieokreślonej topologii, która oparta jest na uwzglednieniu podstawowych cech strukturalnych sieci (liczba węzłów i rozgatęzień, stopień połaczenia z siecia, maksymalna dopuszczalna ranga ścieżek itp.). Aby oszacować strukturalna niezawodność sieci o dowolnej wielkości $i$ dowolnej topologii, badania naukowe proponuja wyrażenia algebraiczne, które określają liczbę ścieżek o różnych rangach, które należy wziąć pod uwage przy obliczaniu wskaźnika niezawodności strukturalnej, używając do tego metody opartej na kresach górnych i dolnych wskaźnika.

Słowa kluczowe: sieć o nieokreślonej topologii, niezawodność strukturalna, ranga ścieżki, liczba ścieżek o określonej randze, górne i dolne kresy

\section{Introduction}

The development strategy of modern communication networks is currently aimed at meeting the growing needs of users and ensuring the required quality of the services. In this regard, there is a tendency to a constant increase in the volume of transmitted data and the complexity of the network structure. The characteristic features of modern networks are the priority use of wireless access and the introduction of self-organization mechanisms into the network. Communication networks are increasingly becoming decentralized, wireless, do not have a constant structure, and the number of nodes and connections between nodes are random variables in time. Each node of such a network can forward data destined to other nodes. The data transfer route is determined dynamically, based on the connectivity of the network at a certain point in time [10]. Moreover, in networks with an undetermined topology, multi-path routing is often used, the aim of which is to provide the source node with the ability to select one of several possible routes to a specific destination node. This approach allows one to optimally use the capacity of the communication channel and increase the overall network bandwidth [8]. Additionally, network fault tolerance and transmission reliability are provided.

A number of scientific papers by A. Ye. Kucheryavy [10], A. V. Roslyakov [15], A. V. Prokopyev, Ye. A. Kucheryavy [9], A. Goldsmith [3], Neha Rathi and others are devoted to the study of modern communication networks with an undetermined topology and elements of self-organization. Most researches note that the use of networks with an undetermined topology has several advantages over networks of a traditional (certain) topology due to the possibility of self-configuration, selfoptimization and self-healing. Such network characteristics allow the adaptation of devices when changing network parameters (for example, the number of users, signal level, level of external interference, etc.) and provide redistribution of functions between devices in the event of failure of any network nodes to increase its reliability and fault tolerance [7]. The introduction of selforganization mechanisms can significantly expand the client base and the range of services provided to network users [10].

Reliability remains one of the network requirements presented in the recommendations of the International Telecommunication Union (ITU-T). So, according to ITU-T Recommendation X.120, the network must be safe, reliable and accessible at any time [16]. The issue of reliability is especially relevant for networks with an undetermined topology. Due to the dynamically changing structure and the lack of centralized management, this type of network is more vulnerable in comparison with fixed topology networks.

The term "network reliability" is understood to mean the property of the network to keep in time within the established limits the values of all parameters characterizing the ability to perform the required functions in the given modes and conditions of use [17]. Network reliability characteristics should provide users with the opportunity to continuously receive services in the conditions of technical failures, operational errors, and also take into account possible threats and risks.

Reliability of networks is ensured by the use of reliable equipment and the introduction of redundancy in the network structure to increase its fault tolerance. Since communication networks with an undetermined topology and elements of selforganization belong to complex structural systems, issues of assessing structural reliability are of particular importance for such networks.

Currently, there are works devoted to the problem of reliability of complex communication systems. These are the works of V. A. Netes [12], N. N. Egunov and V. P. Shuvalov [5], A. V. Kharybin. The structural reliability of self-organized networks is the subject of a number of works by Rudenko and D. A. Migov [11]. In these works, the object of reliability assessment are networks of an initially given structure described by adjacency matrices and other network characteristics. The goal of the classical network analysis problem of a certain topology is to determine the structural reliability of a functioning network or the resulting design solution, presented in the form of some structure [6]. However, in the case where the scale of the network is known, however, the network topology has not yet been determined (at the design stage, for example) or is constantly changing (at the operation stage), for a given (known) set of nodes, the set of branches is unknown. In this case, the network is characterized only by the number of nodes and branches. Therefore, the existing methods for assessing structural reliability, focused on applications for networks with a previously known topology, in cases of networks with an undetermined topology, are of little use.

When considering problems related to the analysis of the structural reliability of communication networks, a random graph is usually used as a network model $[1,2,11,13]$. Among these models classical are, first of all, the Erdős-Rényi $(E R)$ model 
$(G(n, p))$, proposed and studied by the authors at the turn of the 50-60s of the XX century [2], and also its generalization the model $G(H n, p)$ [13].

In addition, various restrictions and refinements of this model are introduced and studied: communications or nodes can be unreliable, the presence of dedicated network nodes, restrictions on the diameter of the network, and others. A large number of studies are carried out in the field where the nodes are considered completely reliable and do not fail. However, a number of works are devoted to the study of the structural reliability of networks where it is nodes that are unreliable, for example, [13].

As a reliability indicator, usually taken are the connectivity probability of the corresponding random graph [13], the average connectivity probability of pairs of vertices [14], or the expected size of the connected component [4]. For networks with a certain topology, a method for obtaining a structural reliability indicator based on taking into account the basic structural characteristics the number of nodes and branches of the network - was proposed in [6]. However, in the indicated papers [1, 2, 4, 6, 11, 13, 14], the issues related to obtaining an estimate of structural reliability for networks of a given dimension (with a given number of nodes and branches) of an undetermined topology are not resolved. Thus, the topic of this work, devoted to the development of a method for obtaining an estimate of structural reliability for a network with a constantly changing structure, is of particular importance and is relevant at present.

\section{Statement of the problem and the methodical basis of research}

The structure of the analyzed generalized network of the undetermined topology is described by a random $E R$-graph (model $G(N, p)$, ER-network). The set of vertices $N$ of the graph corresponds to points (nodes) of the network, $|N|=N$. The set of edges $\boldsymbol{L}$ corresponds to the branches of the network - direct connections connecting pairs of nodes, $|\boldsymbol{L}|=L$. Considered an undirected connected network.

The connectivity between pairs of nodes is provided by routes in the form of chains of branches without cycles and loops. The degree of connectivity of a pair of nodes is determined by the number of routes (in the general case, dependent) connecting these nodes. The rank $R$ of the route corresponds to the number of branches included in the route. In a network of undetermined topology, the set $\boldsymbol{L}$ is not defined, but its cardinality is known $L$. The reliability index of all branches (the probability of failure-free operation of the branch $\left.\beta_{x y}-\left(p_{x y}\right)\right)$ is given $(x, y=\overline{1, n}$. $n$ - number of network nodes, $x \neq y$ ). Network nodes are considered absolutely reliable.

The basis of this paper was the work [7], proposing an approach that provides for the estimation of the structural reliability of a network of undetermined topology, based on taking into account basic structural characteristics. In this paper, to determine the upper and lower boundaries of structural reliability, proposes a method that allows one to determine the number of routes of given ranks that can be used to organize connections $(i-j)$. This makes it possible to obtain an assessment of the structural reliability of both individual connections and the network as a whole.

The indicator of the structural reliability $-P_{I S R}$ for a network is defined as the weighted average value according to the indicators of the structural reliability- $P_{I S R ~ i j}$ of all connections [7]:

$$
P_{I S R}=\frac{\sum_{i=1}^{n} \sum_{j=1}^{n} P_{I S R i j} w_{i j}}{\sum_{i=1}^{n} \sum_{j=1}^{n} w_{i j}}
$$

here $w_{i j}$ is the weight characteristics of individual connections that determine the priority of each connection;

$P_{I S R i j}$ is an indicator of the structural reliability of a single connection $(i-j)$ in the network;

$i, j=\overline{1, n}, n$ is a number of network nodes, $i \neq j$.
Coefficients $w_{i j}$ are not normalized and can be represented in points, for example, in 10- or 100-point rating systems.

To assess the structural reliability of an individual connection (i-j) $P_{I S R i j}$ in the network, presented is the calculation of the indicator of structural reliability as the weighted average of the values of the upper boundary $P_{U B S R i j}$ and the lower boundary $P_{L B S R i j}$ of the structural reliability for a separate connection $(i-j)[6]$ :

$$
P_{\text {ISRij }}=P_{U B S R i j} \cdot k_{U}+P_{L B S R i j} \cdot k_{L},
$$

here $k_{U}$ and $k_{L}$ is the weighted normalized characteristics $\left(k_{U}+k_{L}=1\right)$, that determine the importance (significance) for finding $P_{I S R i j}$ indicators $P_{U B S R i j}$ and $P_{L B S R i j}$, respectively.

Thus, the set of defined routes of rank no more than $R$, realizing communication in the $(i-j)$ direction, and considering them as independent for a given communication, gives an upper bound on the reliability of communication between nodes. Calculation of the upper boundary of the structural reliability $P_{U B S R i j}$ for communication $(i-j)$ in a network with an undetermined topology is carried out in accordance with expression (3) [7]:

$$
P_{U B S R i j}=1-\prod_{\mu_{i j}^{k} \in M_{i j}}\left(1-\prod_{\beta_{x y} \epsilon \mu_{i j}^{k}} p_{x y}\right),
$$

here $\beta_{x y}$ is a section of track $\mu_{i j}^{k}$;

$k$ is a number of the set routes $M_{i j}$;

$p_{x y}$ is the probability of failure-free operation of the $\beta_{x y}$.

The calculation of the lower boundary of the structural reliability of $P_{L B S R i j}$ of an individual connection $(i-j)$ in a network with an undetermined topology is performed in accordance with expression (4) [7]:

$$
P_{L B S R i j}=1-\prod_{\gamma_{i j}^{l} \in \gamma_{i j}}\left(1-\prod_{\beta_{x y} \in \gamma_{i j}^{l}} p_{x y}\right),
$$

here $\gamma_{i j}$ is a set of separating cross sections,

$l$ is a number of cross section set $\gamma_{i j}$;

$\beta_{x y}$ is a branch in a cross section with the corresponding $p_{x y}$ value - the probability of failure-free operation.

The set of dividing sections $\gamma_{i j}$ is formed on the basis of a specific, proposed method using routes between $i$ and $j$, for each $l$-th section $\gamma_{i j}^{l} \in \gamma_{i j}$, the number of section $\beta_{x y}$ is determined using the value $p_{x y}$.

As follows from the presented expressions $(3,4)$, one of the basic structural characteristics used in this method is the number of routes of a certain rank.

In a network with $L$ branches, the number of routes of rank $R$ (more precisely, the mathematical expectation of this number) can be obtained according to the following recursive expression proposed in [6]:

$$
M_{R, L}=M_{R, L+1}\left(1-\frac{R}{L+1}\right),
$$

Since, to determine the number of routes of rank $R$ in a network with $L$ branches, one first needs to calculate the number of routes of rank $R$ in a network with $(L+1)$ branches, recursive calculation begins with calculating the number of routes in a fully connected network with $L_{\text {all }}=\frac{n(n-1)}{2}$ branches $(n$ is the number of network nodes) [6]:

$$
M_{R, L_{\text {all }}}=\frac{n(n-1) !}{2(n-R-1) !}
$$

It is important to note that this method assumes uniformly random saturation of many nodes with branches and, thus, does not take into account the requirements for the formation of a fully connected network. As a result of this, it is possible to obtain the number of routes $M_{L}<1$ for small $L$ and large $R$. This result is consistent with the probabilistic nature of the number of routes in $E R$-networks (as a mathematical expectation) and means that paths with given parameters will not be present in all implementations of a random graph. 
The number of routes of rank $R$ per one connection is calculated as the ratio of the total number of $M_{R}$ routes to the known number $t$ of connections:

$$
m_{R i j}=\frac{M_{R}}{t} \text {. }
$$

The number $t$ of connections can be determined in accordance with expressions $(8,9)$ or it can be a given constant indicator for a particular network

In an oriented network, the total number $t_{o}$ of connections is determined on the basis of expression (8):

$$
t_{o}=n(n-1) \text {. }
$$

If the network is non-oriented, then the total number of $t_{n}$ connections is defined as:

$$
t_{n}=\frac{n(n-1)}{2} .
$$

The above analytical method is not the only one route to obtain the structural characteristics of the network. The number of routes in $E R$ networks of a relatively small dimension can be determined by the simulation of $E R$ graphs.

\section{Research results}

In this research, using the proposed expressions (5-6), a series of experiments was carried out for $E R$ networks of dimensions 20 , 50 , and 100 nodes with a different number of branches: from close to minimum $L_{\text {tree }}$, in which the network is connected (tree), to close to maximum based on expressions (5-6), in which the network is fully connected. To record large numbers, the decimal exponential notation of the form $m \mathrm{E} n=m \cdot 10^{n}$, standard for computer programs, is used.

The experimental results of determining the number of routes of different ranks by the analytical method are presented in tables. Table 1 shows the results of a study for an $E R$ network with a dimension of 20 nodes with a different number of branches (20, 70,120 , and 170 branches).

Table 1. The number of routes of rank $R$ in an ER-network with $N=20$ nodes and $L$ branches

\begin{tabular}{|c|c|c|c|c|c|c|}
\hline \multirow{2}{*}{$L$} & \multicolumn{7}{|c|}{$M_{\mathrm{a}}(N=20)$} \\
\cline { 2 - 7 } & $R=1$ & $R=2$ & $R=3$ & $R=4$ & $\cdots$ & $R=19$ \\
\hline 20 & 20 & 36 & 59 & 86 & & $3.79 \mathrm{E}-07$ \\
\hline 70 & 70 & 460 & 2829 & $1.62 \mathrm{E}+04$ & & $1.20 \mathrm{E}+09$ \\
\hline 120 & 120 & 1360 & 14511 & $1.45 \mathrm{E}+05$ & & $1.11 \mathrm{E}+14$ \\
\hline 170 & 170 & 2736 & 41567 & $5.94 \mathrm{E}+05$ & & $1.31 \mathrm{E}+17$ \\
\hline
\end{tabular}

The number of routes $M_{a}$ of the rank $R=1$ corresponds to a given number of branches $L$. The number of routes of a rank higher than 1 increases with the number of branches and the value of the route rank. In real networks, for the implementation of a single connection, routes of maximum ranks are practically not used for a reason of network performance. Constraints are usually fulfilled at the level of the third or fourth rank. According to this rule, the table shows the calculations of $M_{a}$ for routes for rank $R<=4$.

Tables 2 and 3 show the results of similar calculations for an $E R$ network with $N=50$ and $N=100$ nodes.

Table 2. The number of routes of rank $R$ in an ER network with $N=50$ nodes and $L$ branches

\begin{tabular}{|c|c|c|c|c|c|c|}
\hline \multirow{2}{*}{$L$} & \multicolumn{7}{|c|}{$M_{\mathrm{a}}(N=50)$} \\
\cline { 2 - 7 } & $R=1$ & $R=2$ & $R=3$ & $R=4$ & $\ldots$ & $R=49$ \\
\hline 50 & 50 & 96 & 177 & 314 & & $5.87 \mathrm{E}-23$ \\
\hline 300 & 300 & 3518 & 40285 & 450384 & & $7.29 \mathrm{E}+32$ \\
\hline 550 & 550 & 11841 & 249371 & 5134767 & & $4.04 \mathrm{E}+46$ \\
\hline 800 & 800 & 25067 & 768725 & $2.31 \mathrm{E}+07$ & & $7.68 \mathrm{E}+54$ \\
\hline
\end{tabular}

Table 3. The number of routes of rank $R$ in an ER network with $N=100$ nodes and $L$ branches

\begin{tabular}{|c|c|c|c|c|c|c|}
\hline \multirow{2}{*}{$L$} & \multicolumn{6}{|c|}{$M_{\mathrm{a}}(N=100)$} \\
\cline { 2 - 7 } & $R=1$ & $R=2$ & $R=3$ & $R=4$ & $\cdots$ & $R=99$ \\
\hline 100 & 100 & 196 & 377 & 709 & & $2.00 \mathrm{E}-50$ \\
\hline 350 & 350 & 2419 & 16501 & 111117 & & $3.27 \mathrm{E}+37$ \\
\hline 600 & 600 & 7117 & 83431 & 966571 & & $4.44 \mathrm{E}+63$ \\
\hline 850 & 850 & 14290 & 237560 & $\begin{array}{c}3.90 \mathrm{E}+ \\
06\end{array}$ & & $5.80 \mathrm{E}+79$ \\
\hline
\end{tabular}

The above tables can be used in practical calculations of the reliability of networks of undetermined topology. Using the obtained values of the number of routes $M_{a}$, given in Table 1 , will provide an example of calculating indicator of the structural reliability for a non-oriented communication network with the number of nodes $N=20$ and the number of branches $L=20$.

Based on expressions (7) and (9), we determined the average number of routes of each rank $(R=1, \ldots, 4)$ per one bond $(i-j)$ :

$$
\begin{aligned}
& m_{2 i j}=0.189, \\
& m_{3 i j}=0.311, \\
& m_{4 i j}=0.453 .
\end{aligned}
$$$$
m_{1 i j}=2 \cdot 20 /(20 \cdot(20-1))=0.105
$$

In real systems, devices with a low reliability value are not used. According to statistics, the probability of uptime is usually in the range of $0.96-0.99$. Basing on this, in this example, we take the probability of failure-free operation of the network branches $p=0.98$.

The upper boundary of the structural reliability $P_{U B S R i j}$ is determined by expression (4). Transforming it, according to the source data, obtains the following expression:

$$
P_{U B S R i j}=1-\left((1-p)^{m l i j} \cdot\left(1-p^{2}\right)^{m 2 i j} \cdot\left(1-p^{3}\right)^{m 3 i j} \cdot\left(1-p^{4}\right)^{m 4 i j}\right) \text {. }
$$

Using the given probabilities $p$ of the failure-free operation of network sections and the number of routes $m_{R i j}$ of each rank $(R=1, \ldots, 4)$ per one connection $(i-j)$, obtains:

$$
\begin{aligned}
& P_{U B S R_{i j}}=1-\left(\left(1-0.98^{1}\right)^{0.105} \cdot\left(1-0.98^{2}\right)^{0.189} .\right. \\
& \left.\left(1-0.98^{3}\right)^{0.311} \cdot\left(1-0.98^{4}\right)^{0.453}\right)=0.99999639 .
\end{aligned}
$$

To obtain the value of the lower boundary of the structural reliability $P_{L B S R i j}$, based on the set of routes $M_{i j}$, one should obtain the set of dividing cross sections $\gamma_{i j}$. In order to be able to record the set of cross sections in disjunctive normal form, the values obtained in (10) of the number of routes of each rank per one bond to the nearest larger integer should be rounded off. The result values are:

$$
m_{1 i j}=1, m_{2 i j}=1, m_{3 i j}=1, m_{4 i j}=1 .
$$

Represented a set of paths $M_{i j}$ in disjunctive normal form:

$$
M_{i j}=k_{1}+k_{2} k_{3}+k_{4} k_{5} k_{6}+k_{7} k_{8} k_{9} k_{10} \text {. }
$$

Further, for expression (12), it obtains the dual Boolean function in conjunctive normal form:

$$
\gamma_{i j}=k_{1}\left(k_{2}+k_{3}\right)\left(k_{4}+k_{5}+k_{6}\right)\left(k_{7}+k_{8}+k_{9}+k_{10}\right) \text {. }
$$

Performing the conversion of conjunctive normal form (13) to disjunctive normal form obtains a set of cross sections (14):

$\gamma_{i j}=k_{1} k_{2} k_{4} k_{7}+k_{1} k_{2} k_{4} k_{8}+k_{1} k_{2} k_{4} k_{9}+k_{1} k_{2} k_{4} k_{10}+$

$k_{1} k_{2} k_{5} k_{7}+\cdots+k_{1} k_{3} k_{6} k_{10}$. $P_{\text {LBSRij }}$ :

According to (4), we it obtain the expression for calculating

$$
\begin{aligned}
P_{L B S R_{i j}}=\left(1-\left(1-p_{1}\right)\left(1-p_{2}\right)\left(1-p_{4}\right)\left(1-p_{7}\right)\right) \cdot \ldots \\
\quad \cdot\left(1-\left(1-p_{1}\right)\left(1-p_{2}\right)\left(1-p_{4}\right)\left(1-p_{8}\right)\right) \cdot \ldots \\
\cdot\left(1-\left(1-p_{1}\right)\left(1-p_{2}\right)\left(1-p_{4}\right)\left(1-p_{9}\right)\right) \cdot \ldots \\
\quad \cdot\left(1-\left(1-p_{1}\right)\left(1-p_{3}\right)\left(1-p_{6}\right)\left(1-p_{10}\right)\right) .
\end{aligned}
$$


Transforming (15) according to the initial data we obtain the following expression:

$$
P_{L B S R_{i j}}=\left(1-(1-p)^{4}\right)^{q},
$$

here $q$ defined as:

$$
q=\prod_{R=1}^{4} R^{m_{R i j}} .
$$

Using the given values of the number of routes $m_{R i j}$ of each rank $(R=1, \ldots, 4)$ per one connection and the probabilities $p_{x y}$ of the network branches to fail we obtain:

$$
\begin{gathered}
q=\prod_{R=1}^{4} R^{m_{R i j}}=1^{1} \cdot 2^{1} \cdot 3^{1} \cdot 4^{1}=24 . \\
P_{L B S R_{i j}}=\left(1-(1-0.98)^{4}\right)^{24}=0.99999616 .
\end{gathered}
$$

Based on expression (2) for the values accepted for this example, $k_{U}=0.55$ and $k_{L}=0.45$, the value of the indicator $P_{I S R i j}$ for communication $(i-j)$ is determined:

$$
\begin{aligned}
P_{\text {ISRj }} & =P_{U B S R i j} \cdot 0.55+P_{\text {LBSRij }} \cdot 0.45 \\
& =0.99999639 \cdot 0.55+0.99999616 \cdot 0.45 \\
& =0.99999629 .
\end{aligned}
$$

Performing calculations for all connections $(i-j)$ makes it possible to determine the value of the indicator $P_{I S R}$ of the structural reliability of the entire network (based on expression (1), taking into account the values of weighting coefficients $w_{i j}$ ).

\section{Conclusion}

The paper shows the relevance of the task of assessing the structural reliability of networks of undetermined topology. A method for obtaining such an estimate based on the basic structural characteristics of the network - the number of nodes and branches, the maximum allowable rank of routes, and others is presented. Presented is also a method for determining the number of routes of each rank per one connection. Calculations were carried out for $E R$ networks of dimensions of 20,50 and 100 nodes with different number of branches: from close to the minimum $L_{\text {tree }}$, at which the network is connected (tree), to close to the maximum $L_{\text {all }}$ (fully connected network)

The proposed method for assessing the structural reliability of networks with an undetermined topology is based on the formation of indicator $P_{I S R}$ of the structural reliability, which is determined using the lower and upper boundaries of structural reliability. Expressions are presented for determining the number of routes of different ranks that can be used to service applications that enter the network of the undetermined topology. Based on the upper and lower boundaries of the structural reliability of individual links, presented is an approach that allows one to obtain a weighted average estimate of the structural reliability of the entire network of the undetermined topology.

An example of the implementation of the method for determining the structural reliability indicator of a network of undetermined topology is performed.

Further development of this work is the solution of issues related to the development of approaches to determining the values of the probabilities of failure-free operation of network branches, as well as the values of weighting coefficients for determining the upper and lower boundaries of the structural reliability of both individual connections and the entire network of the undetermined topology.

\section{References}

[1] Bollobás B.: Random Graphs. Cambridge University Press, 2001.

[2] Erdos P. Rényi A.: On random graphs I. Publicationes Mathematicae Debrecen 6/1959, 290-297.

[3] Effros M., Goldsmith A., Médard M.: The Rise of Instant wireless Networks. Scientific American 72/2010, [http://doi.org/10.1038/scientificamerican0410-72].

[4] Youssef M., Khorramzadeh Y., Eubank S.: Network reliability: The effect of local network structure on diffusive processes. Physical Review 88(5)/2013, 052810.

[5] Egunov M., Shuvalov V. P.: Structural Reliability Analysis of Transport Network. Vestnik SibGUTI 1/2012, 54-60.

[6] Kniazieva N. A., Nenov A. L.: A method for assessing the structural reliability of a network when its structure changes. Visnik DUIKT 9(4)/2011, 318-325.

[7] Kniazieva N., Kolumba I.: The Use of the Basic Structural Characteristics of the Network of Uncertain Topology to Assess Its Structural Reliability. Control, Navigation and Communication Systems. Academic Journal 6(52)/2018, 130134, [http://doi.org/10.26906/SUNZ.2018.6.130].

[8] Kolumba I. V.: Characteristic of Multiple-Way Protocols in Wireless SelfOrganized Communication Networks. Visnyk Universyteta "Ukrayina" 21/2/2018, 70-80.

[9] Kucheryavyy A. Ye. et al.: Self-organizing networks. Lyubavich, SanktPeterburg 2011.

[10] Kucheryavyy A. Ye.: Internet of Things and self-organizing networks. Proc. of "Infocommunication technologies in the digital world", SPB GEU LETI, 2012, 3-5.

[11] Migov D.: New network reliability model for wirelles ad hoc networks. Vestnik SibGUTI 3/2014, 3-12.

[12] Netes V. A., Tarasyev Y. I., Shper V. L.: Current issues of terminology standardization in dependability. Dependability $2 / 2014,116-123$.

[13] Raygorodskiy A. M.: Random graph models and their application. Trudy MFTI 4/2011, 130-140.

[14] Rodionov A. S., Rodionova O. K.: Cumulative estimates of the average probability of connectivity of a random graph pair of vertices. Informatics problems 2(19)/2013, 3-12.

[15] Roslyakov A.: Communication networks: manual for the discipline "Communication Networks and Switching Systems", PGUTI, Samara 2017.

[16] Data networks, open system communications and security, ITU-T Recommendations - X series, 04/2008.

[17] Dependability of Technics. Terms and definitions. DSTU 2860-94, Kiev, 1996.

\section{Prof. Nina Kniazieva \\ e-mail: knyazeva@ukr.net \\ Doctor of Technical Sciences (specialty - Telecommunication theory), Professor, Academician of the Ukrainian Academy of Communications (Department of International Informatization Academy, associate member of the UN) \\ Honorary Telecommunications Worker of Ukraine, Professor at the Department of Computer Engineering at Odessa National Academy of Food Technologies. Nina Kniazieva has written over 250 scientific papers.}

http://orcid.org/0000-0002-1523-6775

\section{Ph.D. Alexey Nenov}

e-mail: anotnew@gmail.com

Alexey Nenov was born in 1976 in Odessa. He graduated from Odessa State Polytechnic University with a degree in Robotic Systems and Complexes. In 2014 he defended his thesis with a degree in Telecommunication Systems and Networks. He works as a senior teacher at the Department of Computer Engineering at the Odessa National Academy of Food Technologies.

http://orcid.org/0000-0002-8774-7793

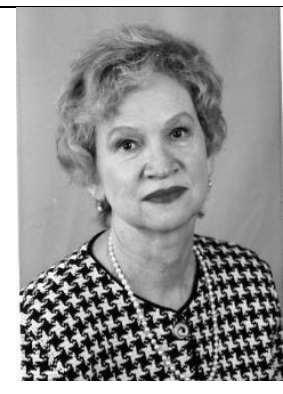

Postgraduate student Irina Kolumba e-mail: iryna.kolumba@ukr.net

Irina Kolumba graduated from the Odessa State Academy of Refrigeration in the specialty "Information systems and technology management" in 2002. Currently she is a postgraduate student and a teacher at the Department of Computer Engineering at Odessa National Academy of Food Technologies.
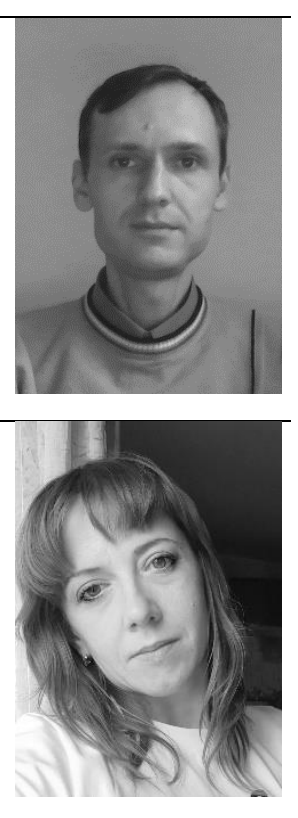